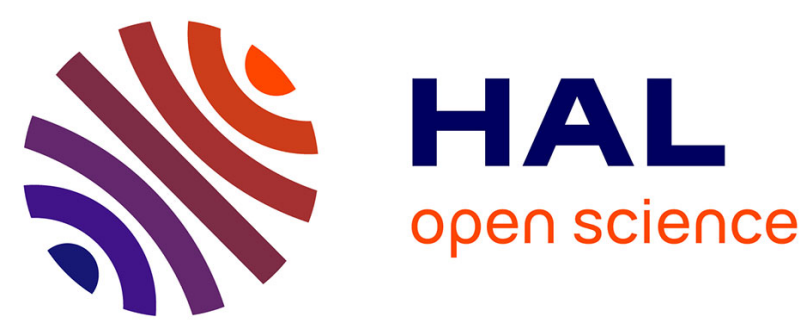

\title{
Rheological Behavior of Zinc-Oxide Nanolubricants
}

\author{
S. Zeinali Heris, M. A. Razbani, P. Estellé, O. Mahian
}

\section{To cite this version:}

S. Zeinali Heris, M. A. Razbani, P. Estellé, O. Mahian. Rheological Behavior of Zinc-Oxide Nanolubricants. Journal of Dispersion Science and Technology, 2015, 36 (8), pp.1073-1079. 10.1080/01932691.2014.945595 . hal-01076551

\section{HAL Id: hal-01076551 \\ https://hal.science/hal-01076551}

Submitted on 17 Apr 2015

HAL is a multi-disciplinary open access archive for the deposit and dissemination of scientific research documents, whether they are published or not. The documents may come from teaching and research institutions in France or abroad, or from public or private research centers.
L'archive ouverte pluridisciplinaire HAL, est destinée au dépôt et à la diffusion de documents scientifiques de niveau recherche, publiés ou non, émanant des établissements d'enseignement et de recherche français ou étrangers, des laboratoires publics ou privés. 


\title{
Rheological behavior of zinc-oxide nanolubricants
}

\author{
Courtel, BP 90422, 35704 Rennes Cedex 7, France

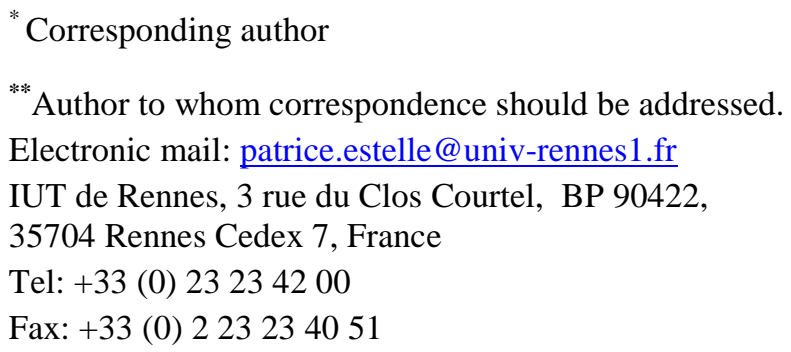

S. Zeinali Heris ${ }^{* a}$, M. A. Razbani ${ }^{a}$, P. Estellé ${ }^{* * b}$, O. Mahian ${ }^{c}$

${ }^{a}$ Chemical Engineering Department, Engineering Faculty, Ferdowsi University of Mashhad, Mashhad, Iran

b LGCGM EA3913, Equipe Matériaux et Thermo-Rhéologie, Université Rennes 1, IUT de Rennes, 3 rue du Clos

${ }^{\mathrm{c}}$ Young Researchers and Elite Club, Mashhad Branch, Islamic Azad University, Mashhad, Iran

\begin{abstract}
We report an experimental investigation of rheological properties of turbine oil-zinc oxide nanoparticle dispersion with different nanoparticle weight fractions ranging from 0.1 to $4 \%$. Rheological experiments were performed within the temperature range of 0 to $60^{\circ} \mathrm{C}$. The results showed that nanolubricants and the base fluid behave like Bingham fluid. Nanolubricant viscosity enhancement as a function of nanoparticle volume fraction is well predicted by Bachelor equation with modified volume fraction. Thereby, rheological data revealed that nanoparticles make aggregates in the turbine oil with diameter about 3.6 of diameter of a single nanoparticle. Moreover, temperature effect on viscosity and yield stress of nanolubricants is shown and discussed.
\end{abstract}

Keywords: nanolubricant, $\mathrm{ZnO}$ nanoparticles, viscosity, yield stress, aggregates 


\section{Introduction}

It is well understood that adding nanoadditives like metal dichalcogenides to common lubricants can enhance their tribological properties [1]. In fact, the nanolubricant approach is used to overcome the disadvantages of conventional anti-wear and friction reduction additives related to their need of chemical reactions with substrates and the resulting induction period to produce the tribofilm on sliding surfaces [2]. These nanoengineered lubricants can also be classified as a new kind of fluid, namely nanofluid [3]. Nanofluids are stable suspensions of particles with less than $100 \mathrm{~nm}$ in diameter dispersed in base fluids (BFs) which are commonly oils and heat transfer mediums like water and ethylene glycol. The most beneficial characteristics of nanofluids are their enhanced thermal properties in comparison to the $\mathrm{BF}$ as reviewed recently by Kleinstreuer et al. [4]. Because one of the main responsibilities of lubricants is heat transfer from heat loaded components, utilizing of nanoparticles as additives in lubricants becomes even more interesting.

One of the most crucial characteristics of lubricants is their rheological properties which are tuned to work in specific conditions. Adding nanoparticles can change these properties like increasing the viscosity of the lubricant that should not be compromised [5]. Regarding the fact that heat transfer characteristics of nanofluid and the tribological properties of nanolubricants have been under focus by researchers more than their rheological properties, addressing these properties in the intersection of nanofluid and lubrication has been discussed previously [6-14]. However, when it comes to mineral based lubricants there are few researches in this field $[6,8-10,13]$. In this work a $\mathrm{ZnO}$ nanoparticle based lubricant was prepared and its rheological properties measured and analysed. To the best of our knowledge, there is no published research that investigated rheological properties of a mineral based lubricant with $\mathrm{ZnO}$ nanoparticles as additive. 
Nanolubricants are mainly prepared dispersing synthesized nanoparticles in common non-polar solvents and mineral oils to provide a stable and transparent solution [15]. Most of the nanolubricants has been made from synthetic based lubricants and have been characterized for their anti-wear and anti-friction properties. For example, Hernandezbattez et al. [16] investigated the tribological behaviour of $\mathrm{ZnO}$ nanoparticles as an additive to PAO6 without addressing rheological phenomena.

From a rheological point of view, nanofluids can be divided into Newtonian [17-19] and non-Newtonian materials [20-22]. Adding nanoparticles to a BF can also change its rheological properties. Determining whether a nanofluid behaves is not straightforward. Some researchers reported that nanofluid behaviour can change from non-Newtonian to Newtonian following test conditions [6,14,23,24]. The main parameters which govern the rheological properties of nanofluids are temperature [7,25], nanoparticle loading [11,12], (3) shear rate [6,14,26,27], aggregation of nanoparticles [8,27,28,29] and morphology of nanoparticles [5,21,30,31].

One of the challenges in producing nanofluids is the aggregation of nanoparticles. There are some theoretical frameworks which deal with this issue in aqueous solutions like extended DLVO theory [32] which describes the stability of nanofluids. The stability of nanofluid becomes more challenging when nanoparticles are dispersed in a non-aqueous BF [33]. The effects of aggregation on the rheological properties of nanofluids were addressed in a lot of researches [18, 27, 34-37]. As explained in $[14,18]$, the presence of aggregates contributed to non-Newtonian behaviour. However, in the case of mineral based nanolubricants, few reports addressed the effects of aggregation on the rheological properties of nanofluid $[8,11]$.

Chou et al. [6] dispersed nanodiamond particles in commercial oil and investigated tribological and rheological properties of nanofluid. They showed that nanofluid behaviour is consistent with Bingham plastic fluid. Among the most recent studies, Kole et al. [8] investigated the effect of aggregation on the viscosity of copper oxidegear oil nanofluids. They reported presence of aggregated $\mathrm{CuO}$ nanoparticles in the fluid, with average cluster size $\sim 7$ times the primary diameter of $\mathrm{CuO}$ nanoparticles. 
The rheological properties of the nanofluid followed Newtonian and shear thinning model at low and high volume fraction of nanoparticles respectively.

Aggregation of nanoparticles in nanofluids can also induce yield stress, which is the required shear stress for a fluid to start to flow. It was shown that the yield stress increased significantly under conditions that were favourable for the formation of complex net-like aggregate structures, such as high solid volume fractions, $\mathrm{pH}$ values near the iso-electric point, and high ionic strengths [38]. In addition, all of the researchers showed that with an increasing nanoparticles volume fraction, the yield stress increases [6, 37, 39-41].

In this work, nanolubricant was prepared dispersing $\mathrm{ZnO}$ nanoparticles in commercial mineral based turbine oil. A full characterization of rheological properties of the resulting nanolubricant is performed. The effects of volume fraction of nanoparticles and temperature are discussed. Appropriate rheological models based on contemporary theories are proposed to correlate and predict the experimental data.

\section{Materials and methods}

\subsection{Nanolubricant}

Rod-like zinc oxide nanoparticles used in this study were supplied by TECNAN Navarrean Nanoproduction Technology. The $\mathrm{ZnO}$ nanoparticles are quite spherical but not necessarily uniform in morphology and can be in the form of aggregates. Behran Turbine SP-1 32 turbine oil was supplied by Behran Oil Company. It is a mineral based oil lubricant and was used as BF for preparing nanofluids. The overwhelming majority of compressors are best served by premium grade turbine oils with ISO viscosities 32 or 46 [42]. According to manufacturer's specifications, the nanoparticles are mainly elongated with an average particle size of $25 \mathrm{~nm}$, with a purity of $99.98 \%$, a density of $5.6 \mathrm{~g} / \mathrm{cm}^{3}$ and a specific surface area of 35 to $50 \mathrm{~m}^{2} / \mathrm{g}$. The density of the Behran Turbine SP-1 32 oil at $15.6^{\circ} \mathrm{C}$ is $0.87 \mathrm{~g} / \mathrm{cm}^{3}$. Its viscosity is $35 \mathrm{cSt}$ at $40^{\circ} \mathrm{C}$, $5.5 \mathrm{cSt}$ at $100^{\circ} \mathrm{C}$, and its viscosity index is 104 . 
Nanolubricants using $\mathrm{ZnO}$ nanoparticles with $0.1,0.5,1.0,2.0,3.0$, and $4.0 \%$ by weight were formulated, which correspond nearly to $0.01,0.07,0.1,0.3,0.4$, and $0.6 \%$ by volume at ambient temperature. Sample preparation was carried out at ambient temperature using a very sensitive mass balance with an accuracy of $0.1 \mathrm{mg}$. Intensive ultrasonication (Misonix Incorporated, Model XL2020) was performed continuously for $2 \mathrm{~h}$ after mixing with BF to possibly de-agglomerate the nanoparticles. Finally, the suspension was homogenized for $1 \mathrm{~h}$ by magnetic force agitation. The prepared nanofluids do not display any visual sedimentation of $\mathrm{ZnO}$ nanoparticles even after keeping the fluids stationary for one day.

\subsection{Rheological measurements}

Rheological behaviour of the nanolubricants and BF was measured with Brookfield programmable viscometer (LVDV-III Ultra) connected to a PC to record the data. WiseCircu temperature controlled bath which can vary the fluid temperature between 20 and $100^{\circ} \mathrm{C}$ and control to $\pm 0.1{ }^{\circ} \mathrm{C}$ was used to stabilize the sample temperature. The viscometer drives a spindle immersed in nanofluid sample. Due to rotation of the spindle, a viscous drag of the fluid against the spindle is developed, which is measured by the deflection of the calibrated spring. Model LVDV-III Ultra viscometer has a viscosity measurement range between 1.3 and 30,000 cP. Spindle SC-18 was used in this study and was calibrated by using Brookfield viscosity standard fluids. The maximum uncertainty was found to be $1.9 \%$. The viscometer contains a sample chamber where the fluid is tested. The temperature inside the sample chamber is carefully monitored using an RTD temperature sensor during the rheological measurements. The spindle type and speed combinations produce satisfactory results when the applied torque is between $10 \%$ and $100 \%$; therefore spindle types and speeds are selected in such a way that the imposed torque values lie in this prescribed range. A wide range of spindle speeds is available in this Viscometer (0-250 RPM). All the measurements were performed under steady state conditions. Tests were done at four different temperatures $0,20,40$, and 60 . 


\section{Results and discussion}

\subsection{Rheological behaviour of turbine oil}

The shear flow behaviour of the turbine oil measured as a function of shear rate between 0 and $60^{\circ} \mathrm{C}$ is shown in Fig. 1. It can be seen that over the measured temperatures and shear rate ranges, the shear stress linearly increases with shear rate. The shear rate range is increased when the temperature increase. Regression of shear flow data can be well fitted by the Bingham fluid model as:

$$
\tau=\tau_{\beta}+\eta \dot{\gamma}
$$

where $\tau$ is the shear stress and $\tau_{\beta}$ is yield stress both in dyn $/ \mathrm{cm}^{2}, \eta$ is the plastic viscosity in Poise $(\mathrm{P})$ and $\dot{\gamma}$ is the shear rate in $\left(\mathrm{s}^{-1}\right)$.

Fitting rheological parameters are presented in Table 1. It is clear that the viscosity of turbine oil increased with decreasing temperature as shown in both Table 1 and Fig. 1. A similar trend is obviously reported for the yield stress of turbine oil.. One of the basic equations that can describe viscosity-temperature relation of mineral based lubricants is Walther-Function which is defined by equation (2).

$$
W=\log (\log (v+\varepsilon))=b-n \log T
$$

in which, $v$ is the dynamic viscosity $\left(\mathrm{mm}^{2} / \mathrm{s}\right), \varepsilon$ is equal to 0.7 for the dynamic viscosity higher than $2 \mathrm{~mm}^{2} / \mathrm{s}$, $\mathrm{T}$ is the temperature in $\mathrm{K}$, and $\mathrm{b}$ and $\mathrm{n}$ are constant coefficients which are determined based on the oil type. Based on the experimental data presented in Table 1, equation (2) leads to the following equation with a regression coefficient of 0.99:

$$
W=\log (\log (v+0.7))=(9.29 \pm 0.07)-(3.64 \pm 0.03) \log T
$$

\subsection{Rheological behaviour of nanolubricants}

Shear stress was measured at different shear rates for all the nanolubricant samples. As for the mineral oil, the shear flow curves of the nanolubricants were linear in form. Then, the Bingham model is also used to describe the shear flow behaviour of nanolubricants. Regression results based on the Bingham model are presented in Table 
2. This table shows that the plastic viscosity of nanolubricants mainly increases with volume fraction and decreases when the temperature is increased.

To study the effects of nanoparticles on the plastic viscosity of nanolubricants, relative viscosity $\eta_{i}$ is introduced, and writes as follows:

$$
\eta_{i}=\frac{\eta-\eta_{0}}{\eta_{0}}
$$

where $\eta$ is the plastic viscosity of nanolubricant and $\eta_{0}$ is the plastic viscosity of the mineral oil.

The relative viscosity versus volume fraction is depicted for $20^{\circ} \mathrm{C}$ in Fig. 2. A second degree polynomial is used to fit the data. Regression coefficient $\left(R^{2}\right)$ is almost equal to unity. A same trend was followed by all nanolubricant samples. The results of fitting $\eta_{i}$ versus volume fraction with a polynomial of the second degree are presented in Table 3. It is observed in particular that the coefficients of the polynomial are quite identical for all temperatures, indicating that the viscosity of nanolubricants seems to be slightly influenced by temperature change, in particular at low volume fraction as discussed later.

More rigorously, a semi-empirical relationship for the relative shear viscosity covering a broad range of particle volume fraction was obtained by Krieger and Dougherty [43]:

$$
\frac{\eta}{\eta_{0}}=\left(1-\frac{\phi}{\phi_{p}}\right)^{-[\eta] \phi_{p}}
$$

$\phi_{p}$ is the critical particle packing fraction, and is approximately 0.605. [ $\eta$ ] is the intrinsic viscosity and equals 2.5 for quite spherical particles. Assuming that hydrodynamic forces are not powerful enough to break the particle aggregation down to individual particles, but increase the volume fraction into an effective volume fraction $\phi_{a}$, equation (4) can be modified as follows to take into account aggregates influence $[17,18,27]$.

$$
\frac{\eta}{\eta_{0}}=\left(1-\frac{\phi_{a}}{\phi_{p}}\right)^{-[\eta] \phi_{p}}
$$


with $\phi_{a}$ given by

$$
\phi_{a}=\frac{\phi}{\phi_{m a}} \quad \text { and } \quad n_{a}=\phi_{m a}\left(\frac{a_{a}}{a}\right)^{3}
$$

where $\phi_{m a}$ is the critical packing fraction of aggregates, $a_{a}$ is the radius of the aggregate, and $n_{a}$ is the number of particles contained in an aggregate. Because aggregates are not growing in a simple order, it is assumed that density of packing decrease with moving along the radius of aggregate. The number of particles in an aggregate also takes the following form $[17,18]$ :

$$
n_{a}=\left(\frac{a_{a}}{a}\right)^{D}
$$

Inserting equation (8) into (7) gives $\phi_{a}$ as follows:

$$
\phi_{a}=\phi\left(\frac{a_{a}}{a}\right)^{3-D}
$$

Combining equations (9) and (6) leads to

$$
\frac{\eta}{\eta_{0}}=\left(1-\frac{\phi}{\phi_{p}}\left(\frac{a_{a}}{a}\right)^{3-D}\right)^{-[\eta] \phi_{p}}
$$

In the previous equations, $\mathrm{D}$ is a measure of how the density of the packing varies along the radius. For nanofluid containing quite spherical particles, D is about 1.8. By substituting $[\eta]$ as 2.5 and $\mathrm{D}$ as 1.8 , equation (10) reduces to

$$
\frac{\eta}{\eta_{0}}=\left(1-\frac{\phi}{0.605}\left(\frac{a_{a}}{a}\right)^{1.2}\right)^{-1.5125}
$$

From equations (3) and (11), the relative viscosity of nanolubricants versus volume fraction $\phi$ is plotted in Fig. 3 for $\left(a_{a} / a\right)$ equals to 1, 3, 3.6, and 4. The case of $\left(a_{a} / a\right)=3.6$ is obtained from fitting the experimental results with the model. In this way, an approximation of aggregation size is obtained from analysing rheological data. 
This aggregate size is about $90 \mathrm{~nm}$. On the other hand, for particle volume fraction less than $4 \%$ which is the case here, the Krieger and Dougherty model reduces to the Batchelor equation [44]:

$$
\frac{\eta}{\eta_{0}}=1+2.5 \phi+6.2 \phi^{2}
$$

So, replacing $\phi$ by $\phi_{a}$, and replacing equation (9) into (12), one obtain:

$$
\frac{\eta}{\eta_{0}}=1+2.5 \phi\left(\frac{a_{a}}{a}\right)^{3-D}+6.2\left(\phi\left(\frac{a_{a}}{a}\right)^{3-D}\right)^{2}
$$

After substituting the value of parameters, the relative viscosity finally becomes:

$$
\eta_{i}=\frac{\eta}{\eta_{0}}-1=11.628 \phi+134.127 \phi^{2}
$$

If one compares equation (14) with the results that are shown in Table 3, it reveals that Bachelor equation can well predict the rheological behaviour of nanolubricants if volume fraction is well replaced by the modified volume fraction.

As stated above, rheological properties of nanolubricant and turbine oil were affected by temperature. Fig. 4 shows that all the nanolubricants follow Walther function with no detectable change in the parameters. This means that the temperature effect seems to be mainly governed by the mineral oil characteristics. To investigate the effect of temperature more precisely, $\eta_{i}$ versus temperature is plotted in Fig. 5. For low volume fraction of nanoparticle, $\eta_{i}$ is almost constant but as the volume fraction grows, $\eta_{i}$ starts to fall gradually with increasing temperature. This behaviour can be possibly attributed to the changes in $\left(a_{a} / a\right)$ and $\mathrm{D}$ with temperature. With regard to equation (11) decreasing $\left(a_{a} / a\right)$ will decrease $\eta_{i}$. One of the factors which may play a role in the size of the aggregates is Brownian movement. The Einstein-Stokes equation can be used to relate Brownian movement [45]:

$$
x=\sqrt{\frac{2 k T t}{3 \pi a \eta}}
$$


in which $a$ is the diameter of particles, $\mathrm{k}$ is the Boltzmann constant, $\eta$ is the viscosity, $\mathrm{T}$ is the temperature, $\mathrm{t}$ is the time, and $x$ is the distance.

Considering equation (15), it is clear that with increasing the temperature, Brownian movement increases. Consequently, increasing Brownian movement increases inter molecular interaction between aggregates especially at high nanoparticle volume fraction which can decrease $\left(a_{a} / a\right)$. Finally, the relative yield stress of nanolubricants is introduced as follows,

$$
\bar{\tau}_{\beta}=\left(\frac{\tau_{\beta}-\tau_{\beta 0}}{\tau_{\beta 0}}\right)
$$

where $\tau_{\beta 0}$ is the yield stress of $\mathrm{BF}$ at the corresponding temperature. Variation $\bar{\tau}_{\beta}$ versus volume fraction at different temperatures is depicted in Fig. 6. First of all, Fig. 6 shows that the relative yield stress of nanolubricants slowly increases for volume fraction lower than $0.3 \%$. For this volume fraction range, the relative yield stress is quite constant for the tested temperature under the experimental and fitting uncertainties. This indicates the slight influence of temperature for this concentration range. For higher volume fraction up to $0.6 \%$, the relative yield stress strongly depends on both volume fraction and temperature. So, it is observed that the higher the volume fraction and temperature, the higher the relative yield stress of nanolubricants. As mentioned above, increasing the temperature increases the Brownian motion of the particles. Particularly, at high concentrations of nanoparticles the preventing role of nanoparticles on clotting will be diminished and then the yield stress increases.

\section{Conclusion}

The rheological behaviour of turbine oil with $\mathrm{ZnO}$ nanoparticles were investigated experimentally as a function of volume fraction and temperature. It was shown that this kind of dispersion behaves like Bingham fluid. To study the effect of the nanoparticle volume fraction and temperature on the viscosity of nanolubricant, Krieger and Dougherty equation was used with modified effective volume fraction. The results showed that nanoparticles are packed within the base fluid in aggregates with diameter 
about 3.6 times of a single particle. Replacing the modified volume fraction with the correct aggregation size into the Bachelor equation well fitted the experimental results within the volume fraction range investigated. This can be helpful to predict nanolubricant viscosity for other concentrations and commercial oils under the presence of nanoparticles aggregates.

Temperature had direct effect on the viscosity of base fluid and nanofluid but nearly the same pattern followed by both of them. Interestingly, at high volume fraction of nanoparticles and high temperatures, the effect of temperature was intensified in such a way that increasing the temperature would weaken viscosity magnifying effect of nanoparticles on nanolubricants. Inversely, the yield stress of nanolubricants is increased with both temperature and volume fraction.

\section{References}

[1] Bakunin, V., Suslov, A., Kuzmina, G. and Parenago, O. (2004) Journal of Nanoparticle Research, 6: 273-284.

[2] Mansot, J., Bercion, Y., Romana, L. and Martin, J. (2009) Brazilian Journal of Physics, 39: 186-197.

[3] Choi, S.U.S. and Eastman, J. (1995) Enhancing thermal conductivity of fluids with nanoparticles, Argonne National Lab., IL (United States).

[4] Kleinstreuer, C. and Feng, Y. (2011) Nanoscale Research Letters, 6: 229.

[5] Timofeeva, E. V., Routbort, J.L. and Singh, D. (2009) Journal of Applied Physics, 106: 014304.

[6] Kedzierski Mark A. (2012) International Journal of Refrigeration, 35: 1997-2002.

[7] Wang, B., Wang, X., Lou, W. and Hao J. (2012) Colloids and Surfaces A: Physicochemical and Engineering Aspects, 414: 125-131.

[8] Yang, Y., Grulke Eric A., Zhang, Z. and Wu G. (2006) Journal of Applied Physics, 99: 4307.

[9] Saeedinia, M., Akhavan-Behabadi, M. A. and Razi, P. (2012) International Communications in Heat and Mass Transfer, 39: 152-159.

[10] Chou, C.C. and Lee S.H. (2008) Journal of Materials Processing Technology, 201: 542-547.

[11] Sarhan, D.A., Sayuti, M. and Hamdi, M. (2012) The International Journal of Advanced Manufacturing Technology, 63: 505-512. 
[12] Sarma Pullela, K., Srinivas, V., Rao, V. and Kumar A. (2011) Nanoscale Research Letters, 6: 233.

[13] Zhou, S-Q., Ni, R.and Funfschilling D. (2010) Journal of Applied Physics, 107/5: 054317.

[14] Kole, M. and Dey, T. (2011) International Journal of Thermal Sciences, 50: 17411747.

[15] Li, B., Wang, X., Liu, W. and Xue, Q. (2006) Tribology Letters, 22: 79-84.

[16] Hernandezbattez, A., Fernandezrico, J., Navasarias, A., Viescarodriguez, J., Chourodriguez, R.and Diazfernandez, J. (2006) Wear, 261: 256-263.

[17] Chen, H., Ding, Y., He, Y.and Tan, C. (2007) Chemical Physics Letters, 444: 333337.

[18] Chen, H., Ding, Y. and Tan, C. (2007) New Journal of Physics, 2007, 9: 367.

[19] Namburu Praveen, K., Kulkarni Devdatta, P., Misra, D. and Das Debendra, K. (2007) Experimental Thermal and Fluid Science 232: 397-402.

[20] Chen, H., Yang, W., He, Y., Ding, Y., Zhang, L., Tan, C., Lapkin, A. and Bavykin Dmitry V. (2008) Powder Technology, 183: 63-72.

[21] Namburu, P., Kulkarni, D., Dandekar, A. and Das D. (2007) Micro \& Nano Letters, 2: 67-71.

[22] Kole, M. and Dey, T.K. (2010) Experimental Thermal and Fluid Science, 34: 677683.

[23] Kole, M. and Dey, T. (2012) International Journal of Thermal Sciences, 62: 61-70.

[24] Estellé, P., Halelfadl, S., Doner, N. and Maré T. (2013) Current Nanoscience, 9: 225-230.

[25] Suganthi, K.S. and Rajan, K.S. (2012) International Journal of Heat and Mass Transfer, 55: 7969-7980.

[26] Phuoc Tran, X. and Massoudi M. (2009) International Journal of Thermal Sciences, 48: $1294-1301$.

[27] Halelfadl, S., Estellé, P., Aladag, B., Doner, N. and Maré T. (2013) International Journal of Thermal Sciences, 71: 111-117.

[28] Pastoriza-Gallego, M., Casanova, C., Paramo, R., Barbes, B., Legido, J. and Pineiro, M. (2009) Journal of Applied Physics, 106: 064301.

[29] Anoop, K.B., Kabelac, S., Sundararajan, T. and Das Sarit K. (2009) Journal of Applied Physics, 106: 034909. 
[30] Halelfadl, S., Maré, T.and Estellé, P. (2014) Experimental Thermal and Fluid Science, 53: 104-110.

[31] Aladag, B., Halelfadl, S., Doner, N., Maré, T., Duret, S. and Estellé, P. (2012) Applied Energy, 97: 876-880.

[32] Boström, M., Deniz, V., Franks, G.and Ninham, B. (2006) Advances in Colloid and Interface Science, 123: 5-15.

[33] Rao, Y. (2010) Particuology, 8: 549-555.

[34] Kwak, K. and Kim C. (2005) Korea-Australia Rheology Journal, 17: 35-40.

[35] Pastoriza-Gallego, M., Lugo, L., Legido, J. and Piñeiro, M. (2011) Nanoscale Research Letters, 6: 221.

[36] Duan, F., Kwek, D. and Crivoi A. (2011) Nanoscale Research Letters, 6, 248.

[37] Tseng Wenjea, J. and Lin, K-C. (2003) Materials Science and Engineering: A, 355: 186-192.

[38] Peng, Z.B., Doroodchi, E., Moghtaderi, B.and Evans G.M. (2012) Advanced Powder Technology, 23: 437-444.

[39] Kinloch, I.A., Roberts, S.A. and Windle A.H. (2002) Polymer, 43: 7483-7491.

[40] Raykar Vijay, S.and Singh Ashok K. (2010) Thermochimica Acta, 502: 60-65.

[41] Tseng, W. and Wu, C. (2002) Acta Materialia, 50: 3757-3766.

[42] Bloch H.P. (2009) Practical lubrication for industrial facilities, $2^{\text {nd }}$ ed., Fairmont Press ; London..

[43] Krieger, I.M.and Dougherty, T.J. (1959) Transactions of the Society of Rheology, 3: 137-152.

[44] Batchelor, G. (1977) Journal of Fluid Mechanics, 83: 97-117.

[45] Einstein A. (1956) Investigations on the Theory of the Brownian Movement, Dover Publications. 


\section{Figure Captions}

Figure 1. Shear flow curves for turbine oil

Figure 2. Regression of $\eta \mathrm{i}$ as a function of volume fraction $\phi$ at $20^{\circ} \mathrm{C}$

Figure 3. $\eta$ i versus volume fraction - Comparison of experimental data and equation (11)

Figure 4. Viscosity versus temperature for nanolubricants

Figure 5. $\eta \mathrm{i}$ versus temperature for nanolubricants

Figure 6. Relative yield stress of nanolubricants versus volume fraction

\section{Table Captions}

Table 1. Regression results for turbine oil based on Bingham fluid model

Table 2. Regression results for nanolubricants based on Bingham fluid model

Table 3. Regression of $\eta_{i}$ as a function of $\phi$ 


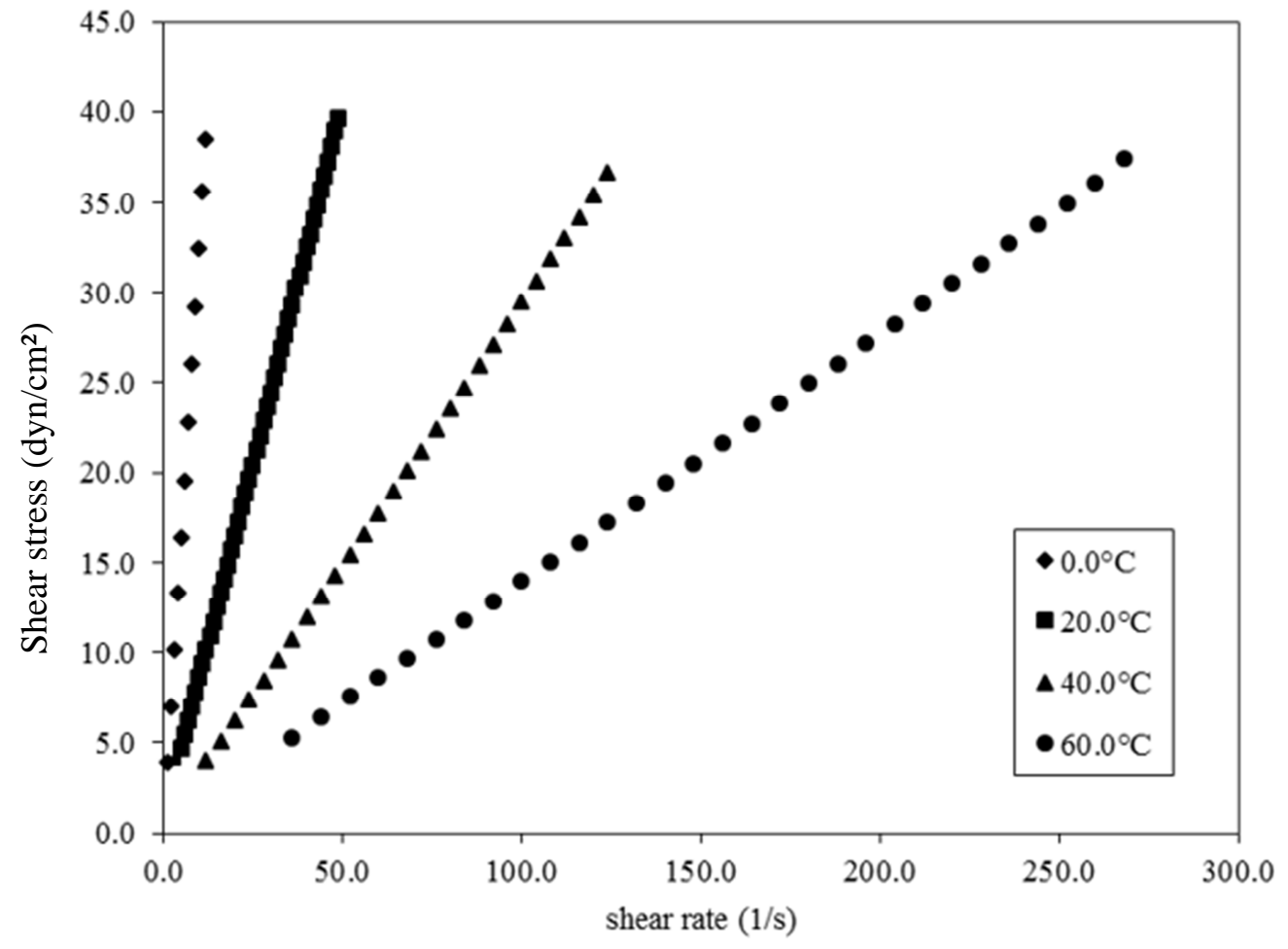

Figure 1. Shear flow curves for turbine oil 


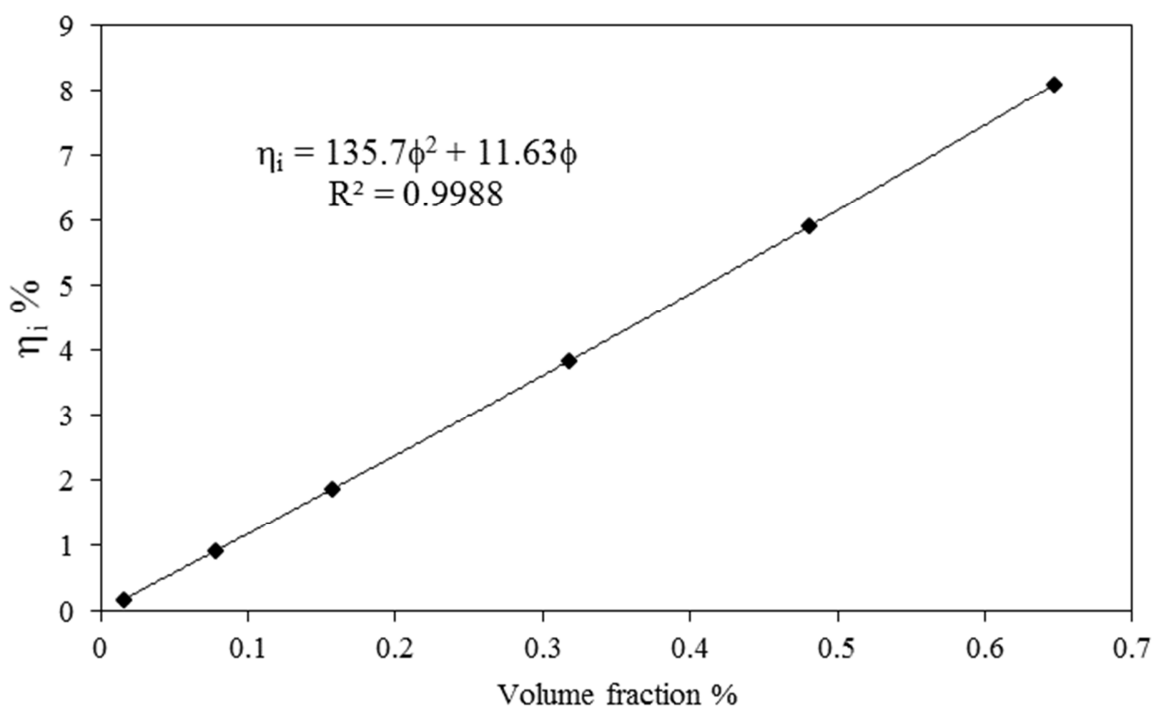

Figure 2. Regression of $\eta \mathrm{i}$ as a function of volume fraction $\phi$ at $20^{\circ} \mathrm{C}$ 


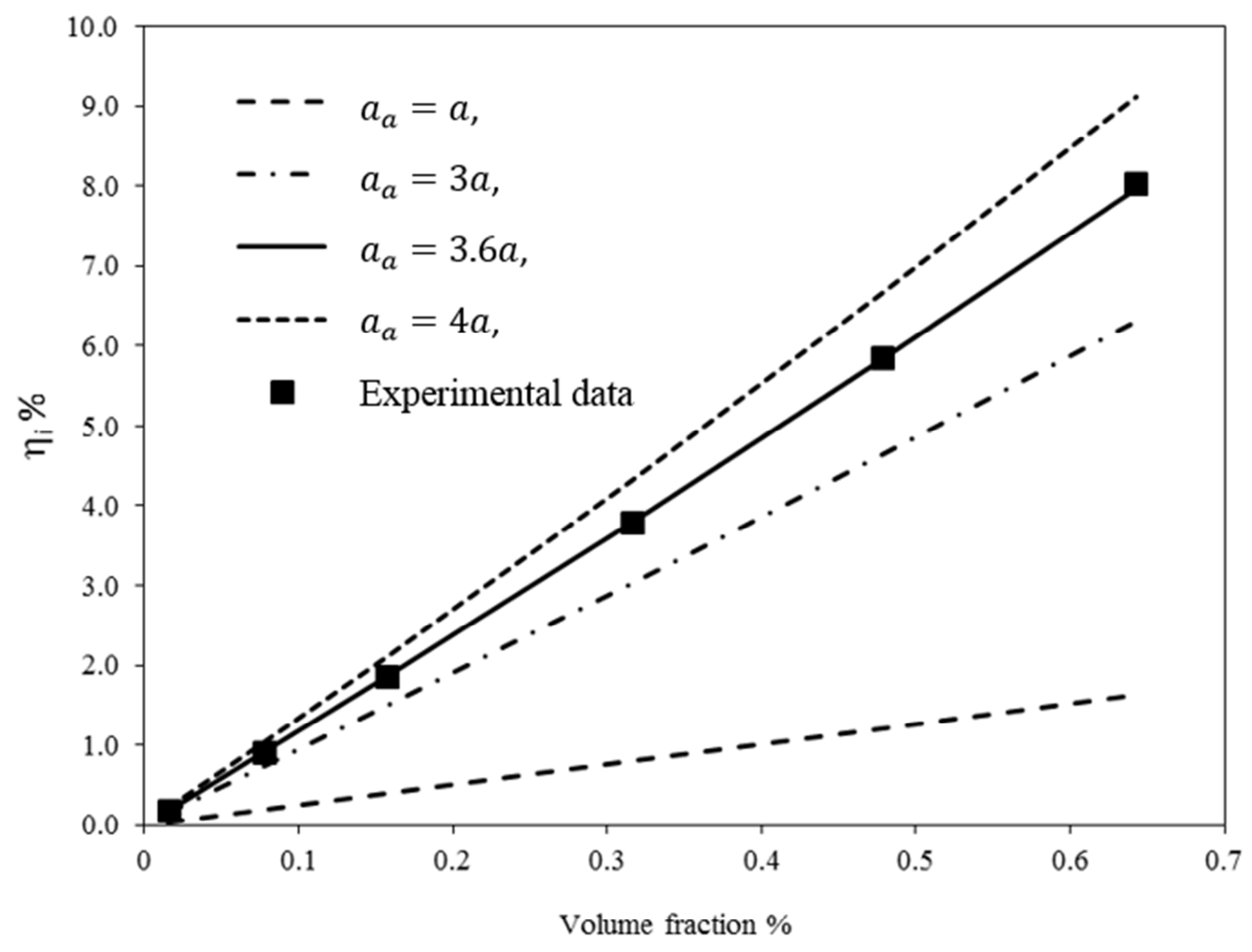

Figure 3. ๆi versus volume fraction - Comparison of experimental data and equation (11) 


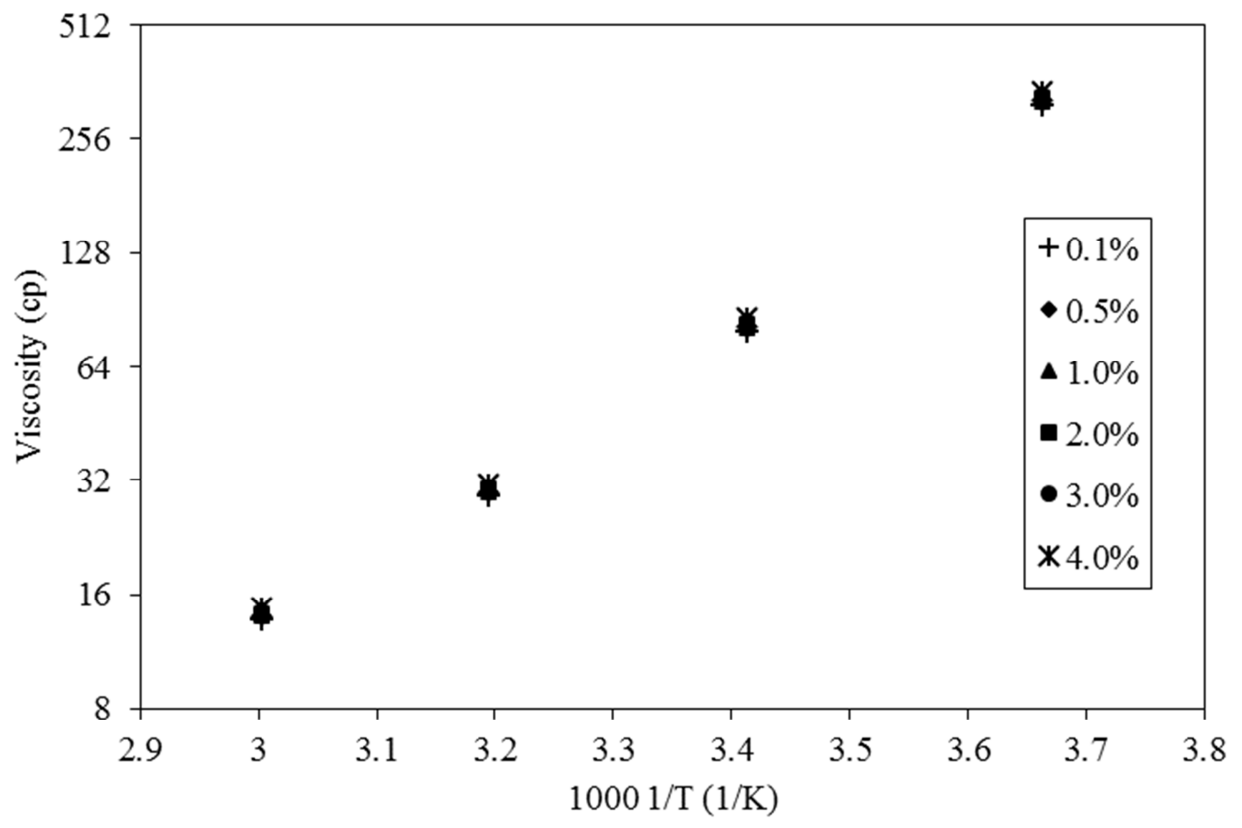

Figure 4. Viscosity versus temperature for nanolubricants 


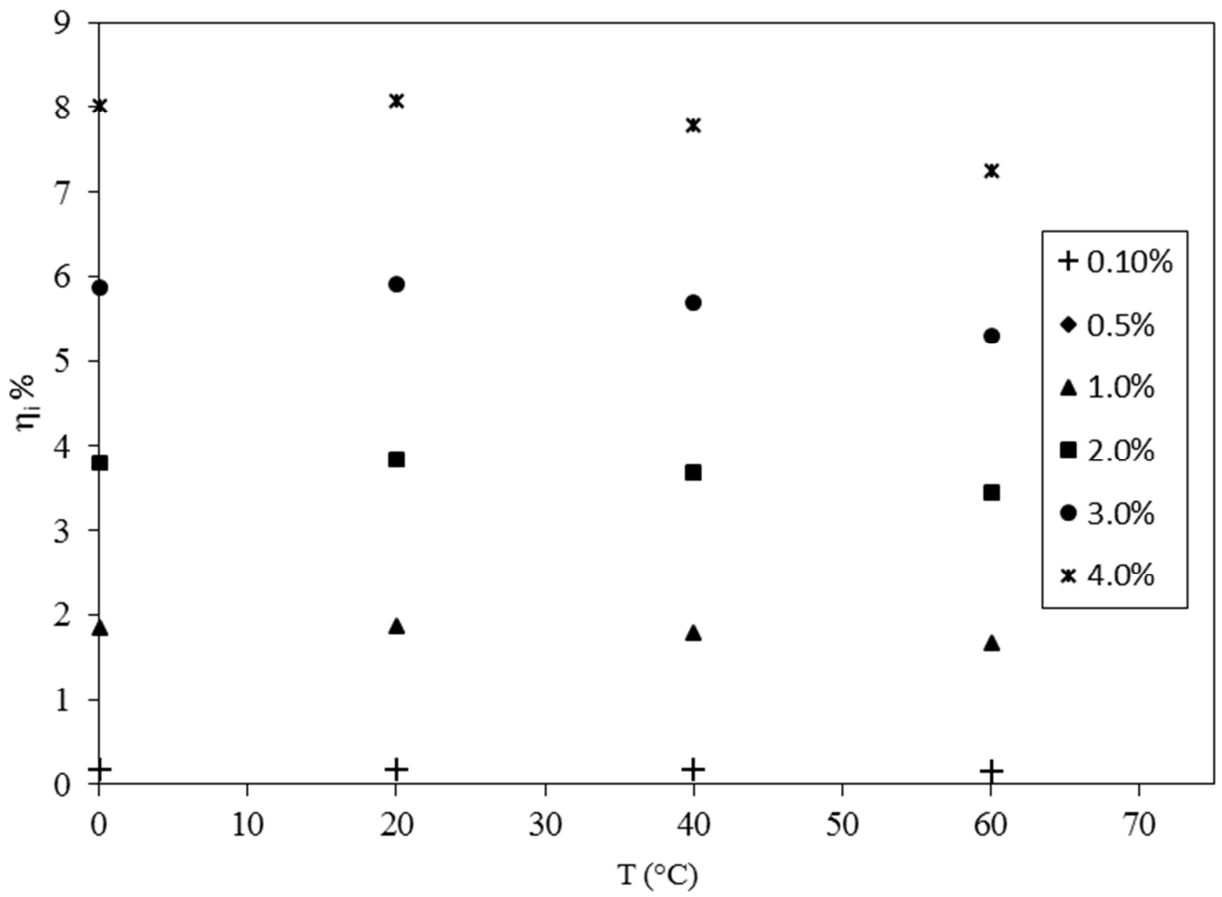

Figure 5. $\eta \mathrm{i}$ versus temperature for nanolubricants 


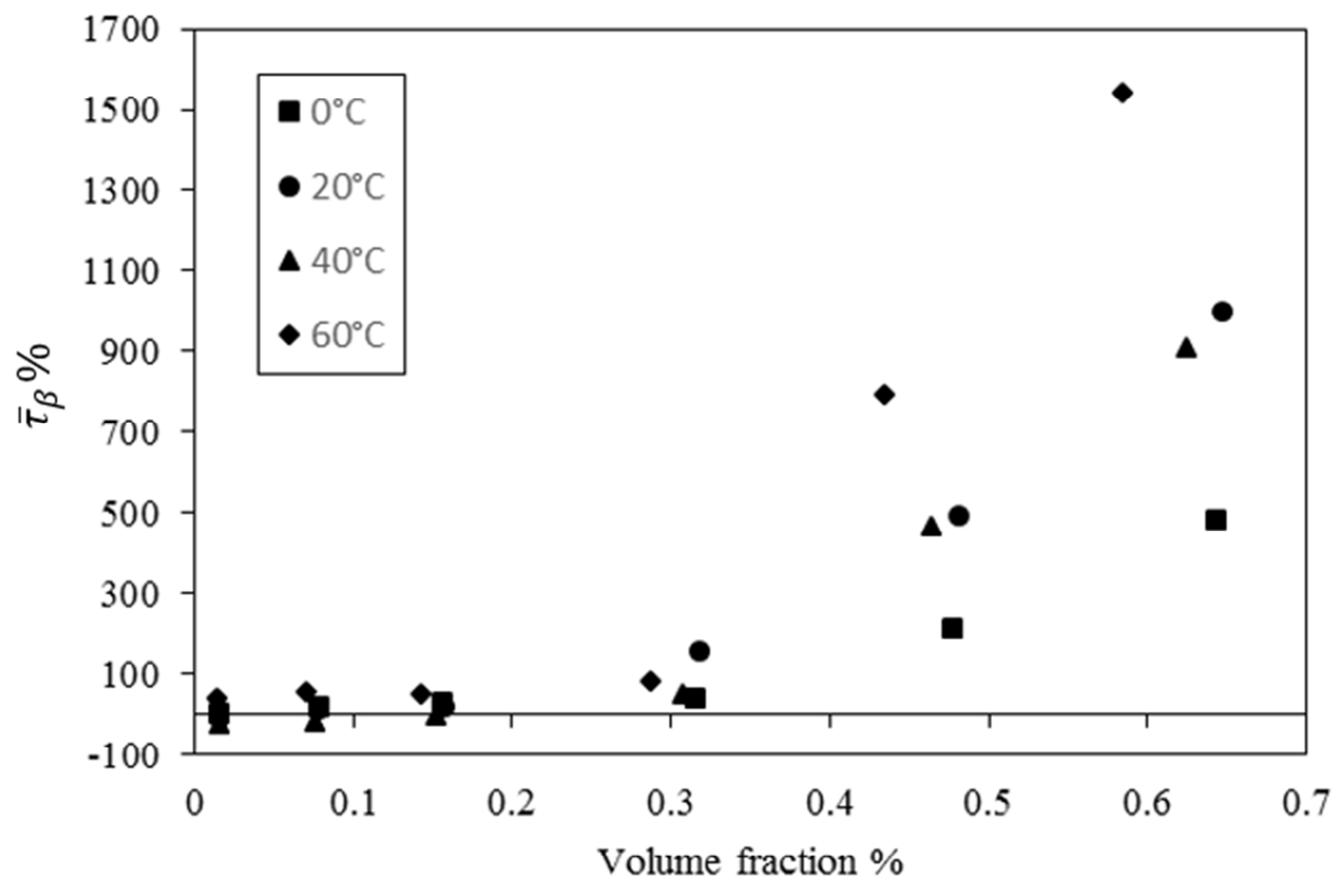

Figure 6. Relative yield stress of nanolubricants versus volume fraction 
Table 1. Regression results for turbine oil based on Bingham fluid model

\begin{tabular}{c|ccc}
\hline $\mathrm{T}\left({ }^{\circ} \mathrm{C}\right)$ & $\eta(\mathrm{cP})$ & $\begin{array}{c}\tau_{\beta} \\
\left(\mathrm{dyn} / \mathrm{cm}^{2}\right)\end{array}$ & $\mathrm{R}^{2}$ \\
\hline 0.0 & $316.6 \pm 0.9$ & $0.67 \pm 0.07$ & 0.9998 \\
20.0 & $79.68 \pm 0.06$ & $0.50 \pm 0.02$ & 0.9999 \\
40.0 & $29.17 \pm 0.04$ & $0.42 \pm 0.03$ & 0.9997 \\
60.0 & $13.75 \pm 0.03$ & $0.27 \pm 0.02$ & 0.9999 \\
\hline
\end{tabular}


Table 2. Regression results for nanolubricants based on Bingham fluid model

\begin{tabular}{|c|c|c|c|c|c|c|c|}
\hline $\mathrm{T}\left({ }^{\circ} \mathrm{C}\right)$ & 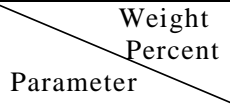 & $0.1 \%$ & $0.5 \%$ & $1.0 \%$ & $2.0 \%$ & $3.0 \%$ & $4.0 \%$ \\
\hline \multirow{3}{*}{0.0} & $\eta(\mathrm{cP})$ & $317.2 \pm 0.4$ & $319.5 \pm 0.4$ & $322.5 \pm 0.9$ & $328.6 \pm 0.8$ & $335 \pm 2$ & $342 \pm 3$ \\
\hline & $\tau_{\beta}\left(\mathrm{dyn} / \mathrm{cm}^{2}\right)$ & $0.7 \pm 0.03$ & $0.81 \pm .03$ & $0.88 \pm 0.06$ & $0.95 \pm 0.04$ & $2.1 \pm 0.1$ & $3.9 \pm 0.2$ \\
\hline & $\mathrm{R}^{2}$ & 0.9999 & 0.9997 & 0.9999 & 0.9999 & 0.9999 & 0.9999 \\
\hline \multirow{3}{*}{20.0} & $\eta(\mathrm{cP})$ & $79.8 \pm 0.2$ & $80.4 \pm 0.1$ & $81.1 \pm 0.11$ & $82.7 \pm 0.2$ & $84.4 \pm 0.6$ & $86 \pm 2$ \\
\hline & $\tau_{\beta}\left(\mathrm{dyn} / \mathrm{cm}^{2}\right)$ & $0.45 \pm 0.07$ & $0.57 \pm 0.03$ & $0.6 \pm 0.03$ & $1.28 \pm 0.06$ & $3.0 \pm 0.1$ & $5.5 \pm 0.3$ \\
\hline & $\mathrm{R}^{2}$ & 0.9999 & 0.9999 & 0.9996 & 0.9999 & 0.9995 & 0.9999 \\
\hline \multirow{3}{*}{40.0} & $\eta(\mathrm{cP})$ & $29.22 \pm 0.08$ & $29.4 \pm 0.1$ & $29.7 \pm 0.1$ & $30.2 \pm 0.1$ & $30.8 \pm 0.2$ & $31.4 \pm 0.4$ \\
\hline & $\tau_{\beta}\left(\mathrm{dyn} / \mathrm{cm}^{2}\right)$ & $0.32 \pm 0.06$ & $0.34 \pm 0.08$ & $0.4 \pm 0.1$ & $0.62 \pm 0.06$ & $2.37 \pm 0.09$ & $4.2 \pm 0.1$ \\
\hline & $\mathrm{R}^{2}$ & 0.9999 & 0.9999 & 0.9997 & 0.9999 & 0.9999 & 0.9999 \\
\hline \multirow{3}{*}{60.0} & $\eta(\mathrm{cP})$ & $13.8 \pm 0.02$ & $13.86 \pm 0.03$ & $13.98 \pm 0.02$ & $14.22 \pm 0.02$ & $14.5 \pm 0.04$ & $14.7 \pm 0.1$ \\
\hline & $\tau_{\beta}\left(\mathrm{dyn} / \mathrm{cm}^{2}\right)$ & $0.38 \pm 0.04$ & $0.43 \pm 0.05$ & $0.41 \pm 0.03$ & $0.5 \pm 0.3$ & $2.41 \pm 0.05$ & $4.43 \pm 0.1$ \\
\hline & $\mathrm{R}^{2}$ & 0.9999 & 0.9999 & 0.9999 & 0.9999 & 0.9997 & 0.9999 \\
\hline
\end{tabular}


Table 3. Regression of $\eta_{i}$ as a function of $\phi$

\begin{tabular}{|c|c|c|c|}
\hline \multirow{2}{*}{$\mathrm{T}\left({ }^{\circ} \mathrm{C}\right)$} & \multicolumn{3}{|c|}{$\eta_{i}=A \phi^{2}+B \phi$} \\
\hline & A & B & $\mathrm{R}^{2}$ \\
\hline 0.0 & 130.5 & 11.65 & 0.98 \\
\hline 20.0 & 135.7 & 11.62 & 0.99 \\
\hline 40.0 & 133.0 & 11.64 & 0.98 \\
\hline 60.0 & 137.2 & 11.61 & 0.99 \\
\hline
\end{tabular}

